\title{
Increased number of endothelial progenitor cells in the blood of patients with psoriasis vulgaris
}

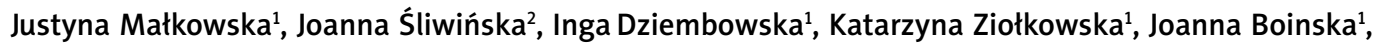 \\ Barbara Góralczyk ${ }^{1}$, Barbara Ruszkowska-Ciastek ${ }^{1}$, Barbara Zegarska², Danuta Rość ${ }^{1}$
}

${ }^{1}$ Department of Pathophysiology, Faculty of Pharmacy, Collegium Medicum in Bydgoszcz, Nicolaus Copernicus University in Torun, Poland

2Department of Cosmetology and Aesthetic Dermatology, Faculty of Pharmacy, Collegium Medicum in Bydgoszcz, Nicolaus Copernicus University in Torun, Poland

Adv Dermatol Allergol 2021; XXXVIII (2): 214-221

DOI: https://doi.org/10.5114/ada.2021.106199

\begin{abstract}
Introduction: Psoriasis vulgaris (PsV) is a common dermatosis characterized by excessive activation of neovascularization. Latest research has shown that endothelial progenitor cells (EPCs) are a crucial factor involved in the repair of endothelial injury and formation of new blood vessels, in a process termed postnatal vasculogenesis. However, the exact mechanism of creating psoriatic skin patches and the involvement of EPCs in this process remains unknown.

Aim: To evaluate the number of EPCs in the blood of patients with PsV, characterized by the expression of specific cell surface markers, including CD45-, CD31+, CD34+ and CD133+.

Material and methods: A total of 49 patients suffering from PsV and 40 healthy volunteers were enrolled in the study. The number of EPCs in each of the volunteers' whole blood samples was measured with a FACSCalibur flow cytometer using monoclonal antibodies directed against antigens specific for EPCs.

Results: The number of EPCs was significantly higher in patients with psoriasis compared with the controls ( $p=$ $0.0007)$ and inversely correlated with disease severity assessed by PASI score $(R=-0.2935, p=0.0407)$. Statistical analysis did not show significant relations between the count of EPCS and age, body mass index, gender, disease duration, blood pressure, extent of itching, severity and frequency of pruritus, presence of bruises, vitamin D supplementation and smoking habit.

Conclusions: The results of our studies indicate that patients with psoriasis showed an increased mobilization of EPCs compared with healthy individuals which correlated negatively with disease severity.
\end{abstract}

Key words: psoriasis vulgaris, endothelial progenitor cells, postnatal vasculogenesis.

\section{Introduction}

Psoriasis is a chronic inflammatory skin disease that affects $2-3 \%$ of the world's population [1, 2]. Some current estimates show that the number of psoriatic patients has even reached as high as 8.5\% [3, 4]. Psoriasis vulgaris (PsV) is the most common form of the disease and it is characterized by the presence of erythematous, scaly papules and plaques mostly located on sufferers' elbows, knees, scalp and trunk [1, 3]. Generally, the etiopathogenesis of psoriasis, is still considered as unknown. The causes are most likely multifactorial and symptoms include epidermal growth and differentiation disturbance as well as immunological, biochemical and vascular disorders [1, 2].

Both capillaroscopic and histological studies have confirmed that psoriatic skin presents numerous abnormalities of blood vessels as a sign of stimulation of neovascularization [5-7]. However, despite a significant progress made in research of this process, the involvement of postnatal vasculogenesis and de novo formation of vessels from endothelial progenitor cells (EPCS) in the pathogenesis of psoriasis remain unclear.

The discovery of circulating endothelial progenitor cells by Asahara et al. in 1997 [8] was a breakthrough

Address for correspondence: Justyna Małkowska, Department of Pathophysiology, Faculty of Pharmacy, Collegium Medicum, Nicolaus Copernicus University, 9 Skłodowskiej-Curie St, 85-094 Bydgoszcz, Poland, phone: +48 525853591 , fax: +48 52 585 3595 , e-mail: justyna.j.malkowska@gmail.com Received: 7.06.2020, accepted: 27.07.2020. 
in understanding the process of neovascularization. It undermined the theory that vasculogenesis takes place only during embryogenesis. However, the definition and description of characteristics of EPCs remain a work in progress. It is believed that they are derived from bone marrow where they constitute $1-5 \%$ of bone marrow stromal cells. In the peripheral blood they represent only $0.01-0.0001 \%$ of mononuclear cells and it is estimated that in a healthy human adult there are 100-200 cells/ $\mathrm{ml}$ [9]. EPCs play an integral role in the regulation and protection of the endothelium and in the maintenance of vascular homeostasis. They are characterized by specific heterogeneity that corresponds with their broad range of abilities: formation of highly specialized cell population with a capacity to regenerate, synthetize growth factors, mobilise other cell populations to support the local angiogenesis process and finally being a source of the differentiated endothelial cells [10-12].

\section{Aim}

The aim of the present study was to evaluate the number of EPCs in the blood of patients with PSV and its association with clinical parameters such as age, body mass index (BMI), gender, disease duration, blood pressure, extent of itching, severity and frequency of pruritus, presence of bruises, vitamin D supplementation and smoking habit.

\section{Material and methods}

The study comprised 49 patients with confirmed diagnosis of PsV (24 males, 25 females). The patients ranged in age from 23 to 74 years ( $45.77 \pm 16.08$ years). All the patients were studied in the dermatology outpatient clinic of the Tadeusz Browicz Provincial Hospital for Infectious Diseases and Observation in Bydgoszcz. Among them, 13 of the patients underwent a course of narrowband ultraviolet-B phototherapy (NBUVB) composed of 30 sessions. This whole body irradiation was performed three times a week using UV Compact Irradiation Cabin GP-42 with SLT2 with a system of therapy control (Cosmedico Medizintechnik, Germany). The initial radiation dose was determined according to the patient's skin phototype based on Fitzpatrick's classification and each individual's skin reaction to the administered NBUVB dose. The patients' blood was collected within 60 min after the last treatment session. None of the patients underwent any pharmacotherapy for at least 3 months prior to the blood collection.

The exclusion criteria were: treatment with antiangiogenic drugs, diseases associated with known involvement of angiogenesis in the pathogenesis of such diseases, cardiovascular diseases (including ischemic heart disease or a history of cerebrovascular accident), hypertension, diabetes, cancer and/or other concomi- tant inflammatory disease. The patients were asked to fill out a questionnaire including questions regarding the patients' demographic data, disease duration, height, weight, type of prior therapy and smoking. The clinical assessment of the disease was based on the Psoriasis Area and Severity Index (PASI) score. Following the recommendations of the Polish Society of Dermatology, the patients with PASI score $>10$ were classified as having a moderate to severe form of psoriasis, while PASI $\leq 10$ indicated a mild form of the disease.

The control group was age (39.77 \pm 11.90 years) and sex (21 males, 19 females) matched and consisted of 40 healthy volunteers who had never suffered from any chronic dermatological diseases.

Written informed consent was obtained from each participant before entering the study. The study was permitted by the Bioethics Committee of Collegium Medicum in Bydgoszcz, The Nicolaus Copernicus University in Torun, Poland (no. KB 246/2014).

Blood samples were collected from the subjects' elbow vein, with minimal venous stasis. The venous blood $(4.5 \mathrm{ml})$, used to identify the number of circulating endothelial progenitor cells (CEPCS), was collected in a fasting state and placed into cooled tubes (Becton Dickinson Vacutainer System, Plymouth, the UK) containing potassium ethylenediaminetetraacetic acid (K2EDTA). Samples were taken after 30 min of rest between 7.30 and 9.30 am and after a 12 h overnight fast. The cell analysis of peripheral blood samples was defined as negative for haematopoietic marker CD45 and positive for endothelial cell markers CD34, CD31 and endothelial progenitor marker CD133.

Cells were further confirmed by fluorescent-activated cell sorting (FACS) Calibur flow cytometer (Becton Dickinson, San Diego, USA) using monoclonal antibodies directed against antigens specific for circulating endothelial progenitor cells (CEPCS). The data acquired were analysed using CellQuest software (Becton Dickinson). CEPCs counts were assessed with the four-colour flow cytometry according to the procedure provided by Mancuso et al. [13].

$50 \mu \mathrm{l}$ of whole peripheral blood was incubated with a fluorescein isothiocyanate (FITC)-conjugated antiCD31, PerCP-Cy5.5-conjugated anti-CD45, as well as APC-conjugated anti-CD34 antibody (all BD Biosciences Pharmingen, San Diego, CA, USA), and phycoerythrin (PE)-conjugated anti-CD133 (Miltenyi Biotec, Bergisch Gladbach, Germany). Circulating endothelial progenitor cells (CEPCS) were defined as negative for hematopoietic marker CD 45, and positive for endothelial progenitor marker CD 133, and positive for endothelial cell markers CD 31 and CD 34. In each sample at least 100,000 events were measured. The total cell count was calculated by using TruCount tubes (BD Biosciences, San Jose, CA, USA) containing a calibrated number of fluorescent beads and; 
"lyse-no-wash" procedures were used in the present study to improve sensitivity.

To determine the concentration of interleukin 6, blood was collected in a $4.5 \mathrm{ml}$ tube without anticoagulant. It was then centrifuged at $3000 \mathrm{~g}$ for $20 \mathrm{~min}$ at $+4^{\circ} \mathrm{C}$ and stored at $-80^{\circ} \mathrm{C}$ until the analysis. Interleukin 6 (IL-6) concentrations were measured using ELISA kit (Diaclone).

\section{Statistical analysis}

All statistical analyses were performed using software Statistica 13.1 (Stat-Soft, Krakow, Poland). Shapiro-Wilk test was applied to assess the normality of distribution. Since the examined parameters showed a non-normal distribution, median (Me) and quartiles (lower - Q1 and upper - Q3) were used. Mann Whitney U test for nonparametric continuous variables was applied to compare the difference between the two subject groups, Kruskal-Wallis

Table 1. Demographic and clinical features of the participants

\begin{tabular}{|c|c|c|}
\hline Variable & $\begin{array}{l}\text { Psoriasis vulgaris } \\
\quad n=49 \\
\text { Min.-max. (mean } \\
\pm \mathrm{SD}) / n(\%)\end{array}$ & $\begin{array}{c}\text { Control group } \\
n=40 \\
\text { Min.-max. (mean } \\
\pm \mathrm{SD}) / n(\%)\end{array}$ \\
\hline \multicolumn{3}{|c|}{ Baseline clinical parameters: } \\
\hline Age [years] & $\begin{array}{c}23-74 \\
(45.77 \pm 16.079)\end{array}$ & $\begin{array}{c}23-64 \\
(39.77 \pm 11.90)\end{array}$ \\
\hline Sex (men/women) & $24(49) / 25(51)$ & $21(52.5) / 19(47.5)$ \\
\hline $\mathrm{BMI}\left[\mathrm{kg} / \mathrm{m}^{2}\right]$ & $\begin{array}{c}17.58-34.87 \\
(25.77 \pm 3.756)\end{array}$ & $\mathrm{N} / \mathrm{A}$ \\
\hline \multicolumn{3}{|l|}{ Medical history: } \\
\hline Systemic treatment & 0 & $\mathrm{~N} / \mathrm{A}$ \\
\hline Phototherapy & $13(26.53)$ & $\mathrm{N} / \mathrm{A}$ \\
\hline Current smoker & $11(22.45)$ & $5(12.5)$ \\
\hline $\mathrm{IL}-6[\mathrm{pg} / \mathrm{ml}]$ & $\begin{array}{c}0.62-45.84 \\
(3.08 \pm 6.616)\end{array}$ & $\begin{array}{c}1.52-10.91 \\
(4.06 \pm 2.018)\end{array}$ \\
\hline $\begin{array}{l}\text { Disease duration } \\
\text { [years] }\end{array}$ & $\begin{array}{c}3-56 \\
(20.64 \pm 2.018) \\
\end{array}$ & $\mathrm{N} / \mathrm{A}$ \\
\hline PASI score & $\begin{array}{c}0.6-22.6 \\
(6.03 \pm 5.256)\end{array}$ & $\mathrm{N} / \mathrm{A}$ \\
\hline
\end{tabular}

BMI - body mass index, PASI - Psoriasis Activity and Severity Index, N/A - not applicable. test for more than two groups and Dunn's test for multiple pairwise comparisons as a post-hoc procedure following rejection of the Kruskal-Wallis test. The relationships between the examined parameters were determined by Spearman's rank-order correlation. Linearized logarithmic regression model was assessed to determine the relation of PASI score and endothelial progenitor cells number in the blood of PsV patients; $p$-value of $<0.05$ was considered significant in all statistical analyses.

\section{Results}

The main demographic and clinical features of patients with PsV and healthy subjects are shown in Table 1. Their mean duration of disease was $20.64 \pm 2.018$ years and mean PASI score was $6.03 \pm 5.256$.

In this work we have demonstrated that the number of EPCs is significantly higher $(p=0.0007)$ in the blood of PsV patients as compared with healthy controls (Table 2). There were no significant correlations between the number of EPCs in PSV patients and such demographic and clinical factors as age, BMI and disease duration. The number of EPCS was significantly negatively correlated with PASI score $(R=-0.2935, p=0.0407)$ (Table 3, Figure 1 ).

To further evaluate the possible relationship between EPCs number and disease severity, patients with PsV were subdivided into those with mild (PASI $\leq 10)$ and those with moderate to severe form of the disease (PASI > 10). The PASI scores in patients ranged from 0.6 to 22.6 points. $79.6 \%$ of the patients were found to have mild psoriasis, whereas moderate or severe disease was detected in $20.4 \%$ of the patients (Table 4 ). These subgroups together with the control group were compared regarding the number of EPCS. The results of these analyses demonstrated no significant difference in the number of EPCs among patients with a mild form of psoriasis and patients with a moderate to severe form. The only significant difference noted was a higher number of EPCs in patients with a mild form of psoriasis in comparison with the control group $(p=0.0004)$ (Table 4).

To evaluate the possible role of NBUVB treatment in the endothelial progenitor cells' metabolism regulation in psoriasis vulgaris, the study group was subdivided into two groups - patients after NBUVB treatment and patients receiving no treatment (Table 4 ). Numbers of EPCs were

Table 2. Number of circulating endothelial progenitor cells in the blood of PsV patients and the control group

\begin{tabular}{|c|c|c|c|c|c|c|c|c|}
\hline \multirow[t]{2}{*}{ Parameter } & \multicolumn{3}{|c|}{$\begin{array}{l}\text { Psoriasis vulgaris } \\
\qquad n=49\end{array}$} & \multicolumn{3}{|c|}{$\begin{array}{c}\text { Control group } \\
n=40\end{array}$} & \multirow[t]{2}{*}{$P$-value } & \multirow[t]{2}{*}{$\eta^{2}$} \\
\hline & $\mathrm{Me}$ & Q1 : Q3 & Min.-max. & $\mathrm{Me}$ & Q1: Q3 & Min.-max. & & \\
\hline $\begin{array}{l}\text { Endothelial } \\
\text { progenitor cells } \\
{[\mathrm{EPCs} / \mu \mathrm{l}]}\end{array}$ & 1.22 & $0.51: 4.48$ & $0.00-43.56$ & 0.51 & $0.25: 0.97$ & $0.00-4.27$ & $0.0007^{*}$ & 0.172 \\
\hline
\end{tabular}

*Significant, $\eta^{2}$, effect size. 
Table 3. Spearman correlation coefficient analyses factors associated with EPC population in PsV patients

\begin{tabular}{lcccc}
\hline Parameter & \multicolumn{2}{c}{$\begin{array}{c}\text { Psoriasis vulgaris } \\
n=49\end{array}$} & $\begin{array}{c}\text { Control group } \\
n=40\end{array}$ \\
\cline { 2 - 5 } & Correlation coefficient & $P$-value & Correlation coefficient & $P$-value \\
\hline Age [years] & -0.0265 & 0.8563 & 0.1388 & 0.3959 \\
\hline BMI $\left[\mathrm{kg} / \mathrm{m}^{2}\right]$ & 0.0307 & 0.5175 & $\mathrm{~N} / \mathrm{A}$ & \\
\hline Disease duration [years] & 0.0957 & 0.5175 & $\mathrm{~N} / \mathrm{A}$ \\
\hline PASI score & -0.2935 & $0.0407^{*}$ & $\mathrm{~N} / \mathrm{A}$ \\
\hline
\end{tabular}

$B M I$ - body mass index, PASI - Psoriasis Activity and Severity Index, *significant.

similar in those groups and as expected, were significantly higher in comparison with the control group (Table 4).

Table 4 also shows the number of circulating endothelial progenitor cells in the group of women and men from the PsV group and from the control group. No significant differences between men and women with PSV were observed. The only (expectable) differences noted were a higher number of EPCS in men with psoriasis in comparison with healthy men $(p=0.0344)$ and a higher number of EPCs in women with psoriasis in comparison with healthy women $(p=0.006)$.

Table 5 presents the clinical details of the group of patients with psoriasis vulgaris. The study group was divided in terms of blood pressure values, extent of itching, severity and frequency of pruritus, presence of bruises, vitamin D supplementation and smoking habits. There were no significant differences in the number of EPCS between the subgroups.

\section{Discussion}

The aim of this study was mainly to assess the size of the circulating endothelial progenitor cells population (CD $\left.45 / \mathrm{CD} 1^{+} / \mathrm{CD}_{34} / \mathrm{CD} 133^{+}\right)$in the blood of 49 patients with psoriasis vulgaris. The results of our study showed that EPCs population was increased in PsV patients in comparison with healthy controls (Table 2). Our results stand in contrast to the findings of other studies. The study by Ablin et al. [14] involving 32 patients with psoriasis showed no significant difference between the number of EPCS (CD34+/133+ and CD34+/KDR+) in psoriasis patients (with or without arthritis) and in controls. Comparable data have been presented by Patschan et al. [15]. Early endothelial progenitor cells colonies and percentages of circulating cells $\left(\mathrm{CD} 133^{+} / \mathrm{KDR}^{+}\right)$were similar in controls and psoriasis/psoriasis arthritis patients. Interestingly, another study reported by Hayek et al. [16], which involved 21 patients with psoriasis, demonstrated a reduced number of EPCS (CD34+/KDR ${ }^{+}, \mathrm{CD}^{+} 4^{+} / \mathrm{CD} 133^{+} /$ $\mathrm{KDR}^{+}$and $\left.\mathrm{CD}^{2} 4^{+} / \mathrm{CXCR}^{+} / \mathrm{KDR}^{+}\right)$in psoriasis patients compared with healthy controls. Similarly, Batycka-Baran et al. $[17,18]$ noticed a lower level of EPCs $\left(C D 133^{+} / K^{2} R^{+}\right)$ in PsV patients $(n=63)$ as well as in psoriasis arthritis patients $(n=24)$ in comparison to the control group. Liu

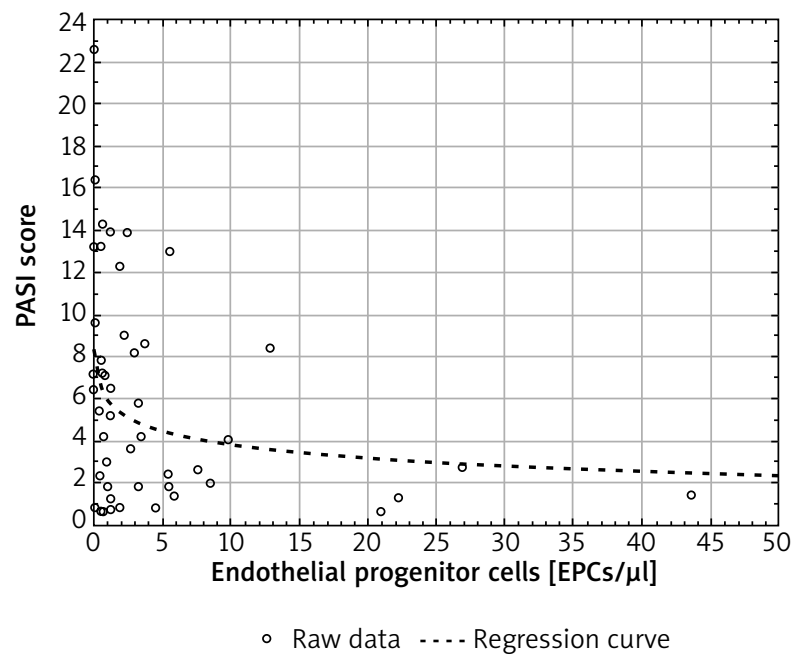

Figure 1. Logarithmic regression of PASI score on endothelial progenitor cells number in the blood of psoriasis vulgaris patients

et al. [19] also found significantly lower levels of circulating CD34+ EPCs in 35 patients with plaque psoriasis compared with controls. The authors of those studies claim that a decreased number of endothelial progenitor cells in psoriasis may be related to the systemic inflammatory process and be a factor predicting the risk of cardiovascular diseases [16-19].

The results reported by those authors [16-19] seem to be in agreement with current knowledge about the role of atherogenesis on EPCs functioning. It is commonly believed that the EPCs number can be used as a predictive biomarker for the cardiovascular risk and vascular function as it is proven to be inversely related to the number of cardiovascular risk factors in patients with known coronary artery disease. Furthermore, reduced numbers of EPCs are estimated to indicate other conditions characterized by both increased inflammation and oxidative stress (diabetes mellitus, heart failure, hypertension, rheumatoid arthritis and preeclampsia) [20].

A number of studies have demonstrated that psoriasis is a systemic inflammatory disease associated with an increased cardiovascular risk [21-26]. The prevalence of traditional cardiovascular risk factors (metabolic syn- 
Justyna Małkowska, Joanna Śliwińska, Inga Dziembowska, Katarzyna Ziołkowska, Joanna Boinska, Barbara Góralczyk, Barbara Ruszkowska-Ciastek, Barbara Zegarska, Danuta Rość

Table 4. Number of circulating endothelial progenitor cells in the blood of PsV patients divided into subgroups and the control group

\begin{tabular}{|c|c|c|c|c|c|c|}
\hline \multirow[t]{2}{*}{ Subgroups } & \multicolumn{4}{|c|}{ Endothelial progenitor cells [EPCs/ $\mu \mathrm{l}]$} & \multirow[t]{2}{*}{$P$-value } & \multirow[t]{2}{*}{$\eta^{2}$} \\
\hline & $n$ & $\mathrm{Me}$ & Q1 & Q3 & & \\
\hline \multicolumn{7}{|l|}{ Disease severity: } \\
\hline Mild form of PsV (PASI $\leq 10)$ & 39 & 1.83 & 0.61 & 5.43 & $0.0005^{*}$ & 0.078 \\
\hline Moderate to severe form of PsV (PASI > 10) & 10 & 0.55 & 0.10 & 0.91 & & \\
\hline Control group & 40 & 0.51 & 0.25 & 0.97 & & \\
\hline $\begin{array}{l}\text { Mild form of PsV vs. Moderate to severe form } \\
\text { Mild form of PsV vs. Control group } \\
\text { Moderate to severe form of PsV vs. Control group }\end{array}$ & & & & & $\begin{array}{c}0.0501 \\
0.0004^{\star} \\
0.9999\end{array}$ & \\
\hline \multicolumn{7}{|l|}{ Treatment: } \\
\hline PsV patients after NBUVB treatment & 13 & 1.21 & 0.41 & 5.53 & $0.0029^{*}$ & -0.021 \\
\hline PsV patients receiving no treatment & 36 & 1.54 & 0.56 & 4.11 & & \\
\hline Control group & 40 & 0.51 & 0.25 & 0.97 & & \\
\hline PsV patients after NBUVB vs. No treatment & & & & & 0.9999 & \\
\hline PsV patients after NBUVB vs. Control group & & & & & $0.0214^{*}$ & \\
\hline PsV patients receiving no treatment vs. Control group & & & & & $0.0034^{\star}$ & \\
\hline \multicolumn{7}{|l|}{ Gender: } \\
\hline Men with PsV (M1) & 24 & 1.87 & 0.46 & 5.48 & & \\
\hline Women with PsV (W1) & 25 & 1.21 & 0.51 & 3.42 & & \\
\hline Healthy men (M2) & 21 & 0.61 & 0.41 & 0.92 & & \\
\hline Healthy women (W2) & 19 & 0.31 & 0.10 & 0.92 & & \\
\hline M1 vs. W1 & & & & & 0.7738 & 0.005 \\
\hline M2 vs. W2 & & & & & 0.1866 & 0.004 \\
\hline M1 vs. M2 & & & & & $0.0344^{*}$ & 0.128 \\
\hline W1 vs. W2 & & & & & $0.0060^{*}$ & 0.134 \\
\hline
\end{tabular}

*Significant; $\eta^{2}$, effect size.

drome, diabetes mellitus, hypertension, obesity, dyslipidaemia and smoking) is higher among patients with psoriasis [24]. Nevertheless, the underlying pathomechanism of increased cardiovascular mortality and morbidity in psoriasis has not been defined precisely.

In the current study, we noticed higher numbers of EPCs in subjects with psoriasis in comparison with the control group. The question arises about the reason for such confounding results. In comparison with other study groups, our cohort group was relatively young; had mild psoriasis (80\% of PsV patients); no arthritis, hypertension, diabetes and an intensive inflammatory process based on IL-6 concentration in the blood (Table 1).

Another point to mention is that the patient population examined was homogeneous with regard to medications. Subjects using anti-psoriatic systemic therapy were excluded from the study. In addition, NBUVB therapy administered to 13 psoriatic patients also did not affect the number of EPCs. We found no significant difference in EPCs number in patients after NBUVB and patients receiving no treatment (Table 4). Nonetheless, PsV patients were characterized by a higher number of EPCs in their blood in comparison with healthy individu- als. We assume that this intensive mobilization of EPCS from bone marrow into the circulation may be attributable to neovascularization that starts with microvascular changes in the papillary dermis of psoriatic plaques and spreads to skin peripheral to psoriatic lesions [5-7].

In the present study, there was a significant inverse correlation of EPCs number and severity of skin involvement assessed with PASI (Table 3). This correlation suggests lower counts of EPCs in those with more severe psoriasis. Indeed, the median value of EPCs in patients with a moderate to severe form of the disease was lower than in patients with mild psoriasis, with the difference bordering on the significant value (Table 4).

It is possible that increasing the size of the sample (especially patients with a moderate to severe form of psoriasis) may have exposed more subtle differences between the groups. Previously, Batycka-Baran et al. [17] found that lower numbers of EPCs in psoriasis patients' blood negatively correlate with PASI. Those authors postulated that such results could be due to an intensification of inflammation related to disease severity. This hypothesis was in part confirmed in another study demonstrating a positive correlation between an important 
Table 5. Detailed clinical characteristics of the patients with psoriasis vulgaris

\begin{tabular}{|c|c|c|c|c|c|c|}
\hline \multirow[t]{2}{*}{ Variable } & \multicolumn{4}{|c|}{ Endothelial progenitor cells [EPCs $/ \mu l]$} & \multirow[t]{2}{*}{$P$-value } & \multirow[t]{2}{*}{$\eta^{2}$} \\
\hline & $\mathrm{N}$ & $\mathrm{Me}$ & Q1 & Q3 & & \\
\hline \multicolumn{7}{|l|}{ Blood pressure: } \\
\hline Prehypertension & 6 & 2.43 & 1.20 & 9.77 & \multirow[t]{3}{*}{0.7719} & \multirow[t]{3}{*}{0.024} \\
\hline Normal & 35 & 1.22 & 0.50 & 5.31 & & \\
\hline Hypotension & 8 & 0.91 & 0.51 & 3.85 & & \\
\hline \multicolumn{7}{|l|}{ Extent of itching: } \\
\hline General & 5 & 0.80 & 0.50 & 3.42 & \multirow[t]{4}{*}{0.9593} & \multirow[t]{4}{*}{0.051} \\
\hline Several locations & 18 & 1.21 & 0.61 & 3.75 & & \\
\hline Single location & 15 & 1.91 & 0.51 & 5.84 & & \\
\hline Lack & 11 & 1.02 & 0.41 & 5.43 & & \\
\hline \multicolumn{7}{|l|}{ Severity of pruritus: } \\
\hline Total irritability & 9 & 0,50 & 0,05 & 4,48 & \multirow[t]{5}{*}{0.5682} & \multirow[t]{5}{*}{0.001} \\
\hline Scratching does not bring relief & 5 & 2.44 & 1.91 & 3.22 & & \\
\hline Demanding scratching & 12 & 1.00 & 0.56 & 14.20 & & \\
\hline Pruritus without scratching & 12 & 2.03 & 0.92 & 4.93 & & \\
\hline Lack & 11 & 1.02 & 0.41 & 5.43 & & \\
\hline \multicolumn{7}{|l|}{ Frequency of pruritus: } \\
\hline $\begin{array}{l}\text { Each episode of prolonged } \\
\text { pruritus (> } 10 \mathrm{~min})\end{array}$ & 12 & 1.43 & 0.51 & 4.32 & \multirow[t]{4}{*}{0.9669} & \multirow[t]{4}{*}{0.012} \\
\hline $\begin{array}{l}\text { Every } 4 \text { short episodes of pruritus } \\
(<10 \mathrm{~min})\end{array}$ & 19 & 1.22 & 0.51 & 5.53 & & \\
\hline Constant itching & 7 & 0.80 & 0.10 & 20.87 & & \\
\hline Lack & 12 & 1.43 & 0.51 & 4.32 & & \\
\hline \multicolumn{7}{|l|}{ Presence of bruises: } \\
\hline Yes & 4 & 1.25 & 0.51 & 5.37 & \multirow[t]{2}{*}{0.7115} & \multirow[t]{2}{*}{0.047} \\
\hline No & 45 & 1.12 & 0.76 & 2.22 & & \\
\hline \multicolumn{7}{|l|}{ Vitamin D supplementation: } \\
\hline Yes & 6 & 1.72 & 0.51 & 5.37 & \multirow[t]{2}{*}{0.8936} & \multirow[t]{2}{*}{0.0001} \\
\hline No & 43 & 1.22 & 0.50 & 4.48 & & \\
\hline \multicolumn{7}{|l|}{ Current smoking: } \\
\hline Yes & 11 & 2.23 & 0.80 & 5.84 & \multirow[t]{2}{*}{0.400} & \multirow[t]{2}{*}{0.015} \\
\hline No & 38 & 1.22 & 0.50 & 3.75 & & \\
\hline
\end{tabular}

*Significant; ${ }^{2}$, effect size.

indicator of inflammation - C-reactive protein and PASI score [14]. The explanation for such negative impact of disease severity on the number of EPCS in our study is less clear. We found no correlation between PASI and IL-6 concentration $(R=-0.034 ; p=0.8185)$. IL-6 concentration was similar in patients with a mild and moderate to severe form of disease ( $M e=2.22 \mathrm{pg} / \mathrm{ml}$ vs. Me $=1.64 \mathrm{pg} / \mathrm{ml} ; p=0.4345$ ). Our results do not support a role for IL-6 in metabolism of EPCs in psoriasis. We can only hypothesize that a decrease in EPCS in more severe cases of PsV is a result of EPCs recruitment and homing into extensively damaged endothelium. Unfortunately, we cannot exclude the participation of inflammation in this process, based only on IL-6 concentration, as other laboratory inflammation markers were not evaluated in this study.

Chronic inflammation observed in psoriasis is largely blamed for endothelial dysfunction and development of atherosclerosis in psoriasis as an accelerator of repetitive vascular injury [26-28]. Interestingly, inflammation can act independently and/or synergistically with the conventional cardiovascular risk factors [22]. The results of studies on the relations between the inflammatory state and EPCs number in patients with psoriasis [27] and psoriatic 
arthritis [14, 18, 29, 30] are divergent. Some, including our study, show no relations between inflammation and EPCs [14, 27], others demonstrate a negative impact of the inflammatory process on the number of EPCs [18, 29, 30]. One cannot forget that the presence of cardiovascular risk factors may also affect the number of these cells. That is why we have found the work of Verma et al. [29] a reliable source of information. The authors of this study decided to minimize factors that have an impact on EPCs, excluded patients who presented traditional cardiovascular risk factors and focused on the role of the inflammation state. They noticed that decreased circulating EPCs correlated inversely with such proinflammatory cytokines as TNF- $\alpha$, IL- 6 and CRP.

The analysis of available research results indicates that the tumour necrosis factor $\alpha$ (TNF- $\alpha$ ) may be a crucial factor involved in the reparative abilities of EPCs in psoriasis. The mechanism is still unclear, however, as far as we know, TNF- $\alpha$ can increase adhesive properties of EPCs to vascular endothelial cells, probably through the system of integrins such as the vascular cell adhesion molecule 1 (VCAM1) and its ligand, very-late antigen 4 (VLA4) [31]. Also, it has been reported that the anti-inflammatory treatment in rheumatoid arthritis with anti-TNF- $\alpha$ agents was proven to increase the number of EPCs in blood [32, 33]. In a later study, Hayek et al. [16] also observed that treatment of psoriatic patients with etanercept, a competitive inhibitor of TNF- $\alpha$, gives almost a two-fold increase in the number of EPCs compared to a placebo. Therefore, psoriasis lesions may be a source of TNF- $\alpha$ responsible for pulling EPCs from the circulation into the areas of ischaemia and/or damaged endothelium. However, it is not certain whether the participation of TNF- $\alpha$ is limited to the process of homing of EPCs, mainly its adhesion phase, or it is extended also to the phase of EPCS mobilization from the bone marrow.

Furthermore, C-reactive protein also plays a key role in the pathogenesis of psoriasis and some previous studies have demonstrated that this inflammatory cytokine's actions impair EPCs differentiation, survival and function [34-36]. Studies on psoriasis have confirmed that the concentration of CRP is inversely correlated with the number of EPCs in the blood of patients with psoriasis (with or without arthritis) [18, 27, 29]. Still, the exact mechanism of action of IL- 6 , TNF- $\alpha$, CRP and other inflammatory cytokines on EPCs in psoriasis is unclear and further research and more extensive studies are needed to understand it better.

\section{Conclusions}

The results of our study indicate that an increased number of endothelial progenitor cells in the blood of patients with psoriasis may be due to an increased mobilization of EPCs in the process of postnatal vasculogenesis. These results also support a negative influence of disease severity on the number of circulating EPCS. However, at this stage of research we cannot explain the mechanism of this process in detail. We are aware that this study has several limitations. As a pilot study, further research should be extended to a greater number of patients. Further analyses are required to estimate other parameters like other inflammatory markers and angiogenic cytokines which may influence the process of neovascularization in psoriasis. On the other hand, the homogeneity of the study group is an undeniable advantage of our project. All patients had not been using pharmacotherapy for 3 months prior to the study, most of them manifested a mild form of the disease and only a few showed risk factors for cardiovascular diseases. These criteria make it possible to minimize the impact of many factors, mainly the therapy with biological agents, on the biology and function of EPCS, which could not be accomplished by the other studies cited.

\section{Conflict of interest}

The authors declare no conflict of interest.

\section{References}

1. Bronckers IM, Paller AS, van Geel MJ, et al. Psoriasis in children and adolescents: diagnosis, management and comorbidities. Paediatr Drugs 2015; 17: 373-84.

2. Eberle FC, Brück J, Holstein J, et al. Recent advances in understanding psoriasis. F1000Res 2016; 28 : 5.

3. Parisi R, Symmons DP, Griffiths CE, Ashcroft DM. Global epidemiology of psoriasis: a systematic review of incidence and prevalence. J Invest Dermatol 2013; 133: 377-85.

4. Kupetsky EA, Keller M. Psoriasis vulgaris: an evidence-based guide for primary care. J Am Board Fam Med 2013; 26: 787-801.

5. Hern S, Stanton AW, Mellor R, et al. Control of cutaneous blood vessels in psoriatic plaques. J Invest Dermatol 1999; 113: 127-32.

6. Heidenreich R, Röcken M, Ghoreschi K. Angiogenesis drives psoriasis pathogenesis. Int J Exp Pathol 2009; 90: 232-48.

7. Liew SC, Das-Gupta E, Chakravarthi S, et al. Differential expression of the angiogenesis growth factors in psoriasis vulgaris. BMC Res Notes 2012; 5: 201.

8. Asahara T, Murohara T, Sullivan A, et al. Isolation of putative progenitor endothelial cells for angiogenesis. Science 1997; 275: 964-7.

9. Sen S, McDonald SP, Coates PT, Bonder CS. Endothelial progenitor cells: novel biomarker and promising cell therapy for cardiovascular disease. Clin Sci 2011; 120: 263-83.

10. Korta K, Kupczyk P, Skóra J, et al. Stem and progenitor cells in biostructure of blood vessel walls. Postepy Hig Med Dosw 2013; 67: 982-95.

11. Hur J, Yoon CH, Kim HS, et al. Characterization of two types of endothelial progenitor cells and their different contributions to neovasculogenesis. Arterioscler Thromb Vasc Biol 2004; 24: 288-93.

12. Ratajska A, Jankowska Steifer E, Czarnowska E, et al. Vasculogenesis and its cellular therapeutic applications. Cells Tissues Organs 2017; 203: 141-52.

13. Mancuso P, Antoniotti P, Quarna J, et al. Validation of a standardized method for enumerating circulating endothelial 
cells and progenitors: flow cytometry and molecular and ultrastructural analyses. Clin Cancer Res 2009; 21: 267-73.

14. Ablin JN, Goldstein Z, Aloush V, et al. Normal levels and function of endothelial progenitor cells in patients with psoriatic arthritis. Rheumatol Int 2009; 29: 257-62.

15. Patschan D, Sugiarto N, Henze E, et al. Early endothelial progenitor cells and vascular stiffness in psoriasis and psoriatic arthritis. Eur J Med Res 2018; 23: 56.

16. Hayek SS, Neuman R, Kavtaradze N, et al. Tumor necrosis factor-alpha antagonism with etanercept improves endothelial progenitor cell counts in patients with psoriasis: etanercept, vascular function and endothelial progenitor cells in psoriasis. Int J Cardiol 2015; 182: 387-9.

17. Batycka-Baran A, Paprocka M, Krawczenko A, et al. Reduced number of circulating endothelial progenitor cells (CD133+/ $\mathrm{KDR}^{+}$) in patients with plaque psoriasis. Dermatology 2012; 225: 88-92.

18. Batycka-Baran A, Paprocka M, Baran W, Szepietowski JC. Decreased number of circulating endothelial progenitor cells $\left(\mathrm{CD} 133^{+} / \mathrm{KDR}^{+}\right)$in patients with psoriatic arthritis. Acta Derm Venereol 2016; 96: 754-7.

19. Liu JH, Chen Y, Zhen Z, et al. Relation between endothelial progenitor cells and arterial stiffness in patients with psoriasis. J Dermatol 2016; 43: 888-93.

20. Du F, Zhou J, Gong R, et al. Endothelial progenitor cells in atherosclerosis. Front Biosci 2012; 17: 2327-49.

21. Mehta NN, Azfar RS, Shin DB, et al. Patients with severe psoriasis are at increased risk of cardiovascular mortality: cohort study using the general practice research database. Eur Heart J 2010; 31: 1000-6.

22. Costa L, Caso F, D'Elia L, et al. Psoriatic arthritis is associated with increased arterial stiffness in the absence of known cardiovascular risk factors: a case control study. Clin Rheumatol 2012; 31: 711-5.

23. Perk J, De Backer G, Gohlke H, et al. European Guidelines on cardiovascular disease prevention in clinical practice (version 2012): The Fifth Joint Task Force of the European Society of Cardiology and Other Societies on Cardiovascular Disease Prevention in Clinical Practice. Eur J Prev Cardiol 2012; 19: 585-667.

24. Horreau C, Pouplard C, Brenaut E, et al. Cardiovascular morbidity and mortality in psoriasis and psoriatic arthritis: a systematic literature review. J Eur Acad Dermatol Venereol 2013; 27: 12-29.

25. Prodanovich S, Kirsner RS, Kravetz JD, et al. Association of psoriasis with coronary artery, cerebrovascular, and peripheral vascular diseases and mortality. Arch Dermatol 2009; 145: 700-3.

26. Boehncke WH, Boehncke S, Tobin AM, Kirby B. The 'psoriatic march': a concept of how severe psoriasis may drive cardiovascular comorbidity. Exp Dermatol 2011; 20: 303-7.

27. Pirro M, Stingeni L, Vaudo G, et al. Systemic inflammation and imbalance between endothelial injury and repair in patients with psoriasis are associated with preclinical atherosclerosis. Eur J Prev Cardiol 2015; 22: 1027-35.

28. Yiu KH, Yeung CK, Chan HT, et al. Increased arterial stiffness in patients with psoriasis is associated with active systemic inflammation. Br J Dermatol 2011; 164: 514-20.

29. Verma I, Syngle A, Krishan P. Endothelial progenitor cell biology in psoriatic arthritis patients in the absence of traditional cardiovascular risk. Indian J Rheumatol 2016; 11: 14-20.

30. Garg N, Krishan P, Syngle A. Atherosclerosis is psoriatic arthritis: a multiparametric analysis using imaging technique and laboratory markers of inflammation and vascular function. Int J Angiol 2016; 25: 222-8.

31. Prisco AR, Prisco MR, Carlson BE, Greene AS. TNF- $\alpha$ increases endothelial progenitor cell adhesion to the endothelium by increasing bond expression and affinity. Am J Physiol Heart Circ Physiol 2015; 308: H1368-81.

32. Ablin JN, Boguslavski V, Aloush V, et al. Effect of anti-TNFalpha treatment on circulating endothelial progenitor cells (EPCS) in rheumatoid arthritis. Life Sci 2006; 79: 2364-9.

33. Spinelli FR, Metere A, Barbati C, et al. Effect of therapeutic inhibition of TNF on circulating endothelial progenitor cells in patients with rheumatoid arthritis. Mediators Inflamm 2013; 2013: 537539.

34. Fujii H, Li SH, Szmitko PE, et al. C-reactive protein alters antioxidant defenses and promotes apoptosis in endothelial progenitor cells. Arterioscler Thromb Vasc Biol 2006; 26: 2476-82.

35. Verma S, Kuliszewski MA, Li SH, et al. C-reactive protein attenuates endothelial progenitor cell survival, differentiation, and function: further evidence of a mechanistic link between C-reactive protein and cardiovascular disease. Circulation 2004; 109: 2058-67.

36. Suh W, Kim KL, Choi JH, et al. C-reactive protein impairs angiogenic functions and decreases the secretion of arteriogenic chemo-cytokines in human endothelial progenitor cells. Biochem Biophys Res Commun 2004; 321: 65-71. 